\title{
A EPIDEMIA DE ZIKA E OS LIMITES DA SAÚDE GLOBAL
}

João Nunes

Professor de Relações Internacionais na Universidade de York,

Reino Unido.Inglaterra.Email<joao.nunes@york.ac.uk>

Denise Nacif Pimenta

Centro de Pesquisas René Rachou-Fiocruz Minas, Fundação Oswaldo Cruz (Fiocruz),

Belo Horizonte, MG. Brasil.Email <denise.pimenta@cpqrr.fiocruz.br >

http://dx.doi.org/10.1590/ 0102-6445021-046/98

\section{A epidemia de Zika na saúde global}

O vírus Zika foi isolado pela primeira vez em 1947 em Uganda, país do continente africano. Seu nome remete a uma floresta local e, literalmente, pode-se traduzir como "coberto" ou "cheio" (Dick, Kitchen e Haddow, 1952; Macnamara, 1954). Foram detectados casos isolados em países de África e, no final da década de 1970, na Indonésia. A partir de 2007, foram descritas epidemias na Micronésia e em outras ilhas do oceano Pacífico. Em fevereiro de 2014, o vírus foi registado pela primeira vez nas Américas, com casos da doença reportados na Ilha de Páscoa (território chileno no oceano Pacífico), provavelmente relacionados com o surto na Micronésia (Musso et al., 2014b). Em 2015, foi confirmada a circulação do vírus no Nordeste do Brasil (Zanluca et al., 2015). Em 2016, desde o mês de maio, 57 países e territórios relatam a continuação da transmissão por mosquito do vírus. Para 44 desses países, este é o primeiro surto de vírus Zika documentado (WHO, 2016).

Se a doença existe desde 1947, porque somente agora a atenção da mídia, da ciência, das agências financiadoras 
e dos órgãos nacionais e internacionais, dentro e fora do setor saúde, a destacam com tanta veemência? De que forma essa epidemia está sendo configurada como um risco social, econômico e político? Quais os efeitos concretos dessa significação e o que está sendo esquecido ou silenciado? São essas perguntas que este artigo almeja refletir ao discorrer sobre a epidemia de Zika no Brasil e a sua relação com a saúde global.

Sugerimos uma visão crítica da saúde global, que considera os contextos sociais, políticos e ideológicos nos quais a Zika é enquadrada e constituída enquanto problema de saúde. Essa abordagem inclui quatro eixos de análise: (1) uma investigação dos processos sociais, culturais e políticos, por meio dos quais ideias sobre saúde e doença são apresentadas, interpretadas, justificadas, legitimadas e contestadas; (2) uma análise das consequências das práticas de significação, ou seja, os efeitos concretos em termos de definição de 22 ações consideradas "necessárias" ou "desejáveis" para resolução ou controle da doença; (3) o estudo das zonas negligenciadas ou silenciadas por esses processos de significação; e (4) uma atenção dada à diversidade de experiências individuais de saúde e doença (não só entre países centrais e periféricos, mas também em nível doméstico).

A aplicação desses eixos de análise ao caso da epidemia de Zika revela interação de múltiplas narrativas e agendas políticas na constituição de significados acerca dessa doença. Para além de evidenciar as tensões, contradições e desigualdades das políticas de saúde no Brasil, a epidemia de Zika ilustra problemas mais abrangentes. As tensões políticas aqui identificadas - referentes ao controle das doenças negligenciadas, determinantes sociais e econômicos, de classe e de gênero - enquadram-se em dinâmicas que ultrapassam as fronteiras do país. Nesse sentido, o processo de significação e as respostas dadas à epidemia mostram os atuais limites da saúde global. 


\section{Elementos para uma crítica à saúde global}

Nos últimos anos, popularizou-se nos meios políticos e midiáticos a ideia de que "a saúde é global". Recentes episódios de alarme internacional - como a gripe H5N1, o Ebola ou a epidemia de Zika - contribuíram para acentuar essa ideia na opinião pública. Apesar de apenas recentemente se ter tornado parte do senso comum, o conceito de saúde global é resultado de um longo processo histórico (Brown, Cueto e Fee, 2006; Birn, 2009; Cueto, 2015). A sua gênese tem sido identificada nas Conferências Sanitárias Internacionais, realizadas a partir de 1851, através das quais se procurou concertar, em nível internacional, as ações de contenção de determinadas doenças infeciosas (Fidler, 2005).

Subjacente à ideia de saúde global está a narrativa de que a globalização aproxima os povos e regiões do mundo, criando uma situação em que todos estão "unidos pelo contágio" (Zacher e Keefe, 2008). Segundo essa narrativa, a globalização significa um aprofundar da cooperação e do consenso, tendo como cenário uma experiência comum um mundo em que, supostamente, as doenças "não conhecem fronteiras". A percepção da saúde enquanto fenômeno global está enquadrada numa visão essencialmente apolítica da governança à escala mundial, assente na crença da capacidade humana de desenvolver soluções técnicas (tecnológicas, farmacológicas, administrativas ou burocráticas) para responder a crises ou problemas (Cooper, Kirton e Stevenson, 2009). A figura legal da "emergência sanitária" internacional, invocada recentemente por ocasião das epidemias de Ebola e de Zika, é um exemplo da importância dada a essas soluções de caráter técnico.

Mas a saúde global é mais do que o resultado de "ameaças comuns" e "crescente cooperação". A problematização das doenças em relação aos movimentos populacionais e ao espaço geográfico não pode ser separada de dinâmicas que são, na sua gênese, de âmbito político e social. Uma visão 
mais abrangente das ideias de saúde e doença revela uma história de permanente tensão e conflito. Um exemplo é a ansiedade relacionada aos imigrantes, aos estrangeiros, aos que são ou parecem ser "diferentes" (em termos raciais, religiosos e outros), que são vistos ora como portadores de doenças, ora como fardos para os sistemas de saúde (Kraut, 1994; Markel, 1997; Shah, 2001). As comunidades políticas - com uma ideia de um "eu" íntegro e seguro - dependem em grande medida da exteriorização de ameaças. A busca de proteção ou "imunidade" em face das doenças infeciosas vindas do exterior tem sido frequentemente considerada parte da constituição de comunidades políticas (Martin, 1994). A medicina e as medidas sanitárias vão, nesse contexto, para além do âmbito estrito da saúde: tornam-se instrumentos políticos que demonstram a mobilização de poder (Foucault, 1977, pp. 195-200). A história da medicina tropical demonstra isso mesmo no contexto das relações entre 24 metrópole e colônia (Edmond, 2006; Anderson, 2006).

O reconhecimento dessa dimensão política coloca em xeque a ideia de saúde global fundada nos pressupostos de uma experiência comum (o problema) e de um aprofundamento da convergência e cooperação (a solução desejável). Permite-nos revisitar os esforços de cooperação internacional e identificar a presença de interesses, agendas, conflitos e formas de poder (Fassin, 2012). As Conferências Sanitárias Internacionais, por exemplo, pautaram-se, desde o início, por uma preocupação fundamental com a proteção do comércio internacional. O objeto dessas conferências não era propriamente a proteção da saúde pública, mas sim a concertação de políticas, tendo em vista o controle da circulação de pessoas e produtos (King, 2002). Esse controle não era baseado na restrição de movimento, mas no princípio da triagem, ou seja, a separação de pessoas e produtos "desejáveis" (cuja circulação é facilitada) dos "indesejáveis". Essa preocupação está presente na mais 
recente versão dos Regulamentos Sanitários Internacionais (2005). Nessas normas, é possível testemunhar uma relação estreita no projeto político global entre saúde, capitalismo e uma mundividência liberal assente na promoção de certas formas de vida econômica útil (e na consequente desautorização e mesmo repressão de outras formas de vida). A cooperação internacional surge, portanto, marcada por uma preocupação fundamental: a contenção de determinadas doenças infeciosas, impedindo a sua chegada ao mundo desenvolvido ocidental.

A partir do momento em que começamos a explorar essa dimensão política na saúde global, torna-se evidente que as visões técnicas são tudo, menos "apolíticas". $\mathrm{Na}$ verdade, elas fazem parte de um processo e uma agenda políticos. A máscara de neutralidade e cientificidade funciona para obscurecer o fato de a saúde global ser, desde a sua gênese até as suas formas mais contemporâneas, um local de reprodução de lógicas de exclusão e negligência; ela reflete estruturas e relações políticas globais que promovem a desigualdade, a vulnerabilidade e a desvantagem de alguns grupos e regiões - como veremos a seguir, a propósito da epidemia de Zika.

É nesse contexto de identificação das estruturas e relações políticas subjacentes às políticas de governança da saúde que se torna pertinente falar de uma abordagem crítica à saúde global. Essa abordagem parte do reconhecimento da dimensão política, social e ideológica e abrange quatro eixos.

O primeiro deles remete à necessidade de uma investigação dos processos sociais e culturais através dos quais ideias acerca da saúde global são apresentadas, interpretadas, justificadas, legitimadas e contestadas. Essa análise permite-nos compreender como se constitui a significação de saúde global. Essa significação não é, porém, unívoca, no sentido de resultar num entendimento universalmente aceito. 
Como veremos, no caso da epidemia de Zika, a constituição de significados revelou a interação de múltiplas arenas de significação e agendas políticas.

O segundo eixo configura-se como uma abordagem crítica, que implica analisar as consequências desse processo de significação; em outras palavras, vislumbrar quais são os efeitos concretos da definição de práticas consideradas “necessárias" ou "desejáveis". Os conceitos ajudam a definir os limites da imaginação política: podem ser considerados como "causas", no sentido em que funcionam como condições potenciais de determinadas medidas práticas. Assim, conhecer a forma como a saúde global é conceitualizada permite-nos entender o contexto no qual as políticas concretas são definidas e executadas.

Um terceiro eixo é o estudo das zonas negligenciadas. A negligência em questões de saúde precisa ser enfocada na sua complexidade: não se trata unicamente da invisibilidade 26 ou silêncio em relação a determinados assuntos, mas, precisamente, da forma como determinados assuntos ou grupos se tornam visíveis ou invisíveis nesse processo. A negligência pode estar presente mesmo quando é dada muita atenção a determinado assunto, pois a qualidade dessa atenção pode ser superficial, passageira ou não considerar aspectos subjacentes importantes. A recente epidemia de Ebola é um bom exemplo dessa dinâmica em que o espetáculo midiático em relação a uma epidemia nem sempre conduz a uma resolução dos problemas estruturais que lhe deram origem (Nunes, 2016).

Este artigo vai analisar o caso da atual epidemia de Zika e mostrar que, apesar de essa doença estar recebendo no momento muita atenção pela mídia e outros órgãos dentro e fora do setor saúde, certos aspectos permanecem negligenciados em decorrência da preponderância de um discurso técnico e biomédico orientado majoritariamente para o controle de mosquitos, configurando o controle da doença 
em "políticas de Aedes" (Pimenta, 2016). Entre esses aspectos negligenciados estão a problemática dos direitos reprodutivos e aborto, a saúde materna, os determinantes sociais da doença, as questões infraestruturais dos sistemas de saúde e de gestão das cidades, os quais permitem que os mosquitos e a doença se espalhem e se reproduzam.

Um quarto eixo refere-se à atenção dada à diversidade de experiências individuais de saúde e doença (não só entre os países mais ou menos desenvolvidos, mas também em nível doméstico). A experiência de "estar doente" ou "ser saudável" não é uniforme, mas sempre contextual, dependente de variáveis como a situação social e econômica, o gênero, a raça, a orientação afetiva e sexual, a idade ou a existência de incapacidades. Essas variáveis têm impacto sobre a vulnerabilidade de um indivíduo ou grupo a determinada doença, sobre o efeito dessa doença na trajetória de vida e também sobre a capacidade de esse indivíduo ou grupo ser capaz de reagir quando a doença ocorre. Nesse contexto, uma abordagem crítica à saúde global assume-se como multidisciplinar. Os contributos da sociologia, da antropologia e outras ciências sociais e humanas são determinantes para uma investigação minuciosa de experiências, que, por sua vez, serão analisadas à luz de condições estruturais e políticas mais abrangentes.

\section{Zika e seus significados}

De que forma os eixos de uma abordagem crítica podem ser mobilizados para melhor compreensão da epidemia de Zika? Comecemos pelo primeiro dos eixos anteriormente identificados, analisando de que forma essa epidemia foi enquadrada e constituída como "problema" de saúde pública e global.

A infecção por Zika não é uma situação nova no mundo. No entanto, o vírus Zika era praticamente desconhecido até o atual surto, que mobilizou os agentes políticos 
nacionais e internacionais e capturou a atenção mundial. Essa atenção deve-se não propriamente à doença em si, mas à sua associação entre as infecções em grávidas com aumento anormal da incidência de microcefalia em recém-nascidos, além da associação com outras doenças como a síndrome de Guillain-Barré, uma doença autoimune neurológica.

Outras doenças transmitidas por mosquitos também têm sido associadas a um risco aumentado da síndrome de Guillain-Barré. No entanto, a magnitude da doença em pessoas não grávidas tem sido tanto qualitativa como quantitativamente ofuscada por seu impacto dramático sobre a gravidez e a associação com a microcefalia. Desde então, a epidemia tem mobilizado gestores, mídia, pesquisadores e sociedade em geral, em reações dramáticas que, não raras vezes, assumiram os contornos de grande alarmismo e até de "zikafobia" (González, 2016).

A "novidade" da Zika e o fato de estar rodeada de muitas incógnitas no meio científico - nomeadamente acerca da forma de transmissão da doença e da relação entre o vírus e as complicações neurológias - fez com que se tornasse urgente dar sentido ao que acontecia. Assim, crescente mobilização de atores políticos e sociais gerou diversas formas de significação e representação da doença. Pode afirmar-se que, em pouquíssimo tempo, desde que entrou na agenda da saúde global, a doença teve orquestradas ao seu redor diversas arenas de significação - a ponto de alguns autores apontarem a Zika como uma "epidemia de significação" (Shum, 2016). Essa ideia de significação segue o conceito de Treichler (1987), segundo o qual epidemias tendem a se configurar em "para-raios" de diversas tensões e dinâmicas sociais e políticas: relações entre classes, culpabilização econômica, racismo, xenofobismo, iniquidade de gênero, entre outras.

Considerada inicialmente como "benigna" e "exantemática”, a doença pelo vírus Zika não suscitou muita atenção 
do setor saúde e dos políticos até o final de 2015, quando foi associada a complicações neurológicas. Foi então que se tornou uma "emergência”, não só no Brasil, mas em nível mundial. Em novembro de 2015, o Brasil declarou Emergência em Saúde Pública de Importância Nacional, utilizando-se pela primeira vez o mecanismo criado em 2011 (Brasil, 2011). Mais tarde, em fevereiro de 2016, a Organização Mundial de Saúde (OMS) decretou emergência sanitária internacional. O uso dessa figura jurídica - utilizada anteriormente nos casos da gripe H1N1, do poliovírus e do Ebola - enquadrou a doença como ameaça à segurança e como evento de risco (Ventura, 2016). No contexto de uma tendência de securitização da saúde à escala global, a declaração de emergência refere-se não apenas a perigos concretos no presente, mas também a incertezas que podem configurar perigos e oportunidades futuras (Weir e Mykhalovskiy, 2010). O "evento" que provocou a declaração de emergência não foi apenas a doença pelo vírus Zika, mas a associação entre Zika e microcefalia, que se encontrava a essa altura ainda revestida de mistério e incerteza (Heymann, 2016).

A definição da epidemia como uma emergência interagiu com outros processos de significação, que revelam múltiplas dimensões do problema político, econômico e social. Após a associação com a microcefalia, configurou-se também a epidemia como um "problema de gênero". De fato, essa associação trouxe à tona questões importantes de saúde materna e direitos reprodutivos das mulheres, não só no Brasil, como na América Latina e no restante do mundo. Demonstrando a diversidade nas experiências da doença, a Zika revelou-se como um risco especial para mulheres gestantes ou em idade fértil. Autoridades públicas têm advogado em prol do gerenciamento de gravidez, contracepção e até abstinência sexual durante a gravidez - trazendo de volta um discurso ideológico sobre a liberdade e sexualidade femininas. 
Outro aspecto de significação relaciona-se ao modo de transmissão da doença. Em grande medida, a Zika vem sendo representada como um "problema de mosquitos" ou de "guerra aos mosquitos" (Pimenta, 2016). A transmissão do vírus por mosquitos Aedes aegypti em ratos e macacos foi comprovada em laboratório em 1956 (Boorman e Porterfield, 1956). Apesar de se afirmar que o Aedes aegypti é o principal vetor, a transmissão do vírus por Aedes africanus foi confirmada; na epidemia de Yap, na Micronésia, em 2007, não havia Aedes aegypti e sim Aedes hensilli; e, na Polinésia Francesa, a transmissão do vírus Zika muito provavelmente foi carregada por Aedes polynesiensis (Valle, Pimenta e Aguiar, 2016). Mais recentemente, o vírus foi detectado no Aedes albopictus no México (PAHO/WHO, 2016) e até mesmo no Culex quinquefasciatus (Ayres, 2016), apesar de necessitar de mais evidências para comprovações do seu real papel na transmissão do vírus. Tomar a Zika como somente um "pro30 blema de mosquitos" está relacionado com a preponderância de medidas de controle do vetor, que, historicamente, tem dominado o discurso e pensamento biomédico sobre as formas possíveis de controle da doença. Tal discurso e preponderância do foco no vetor se deu da mesma forma para a febre amarela no século passado e, mais recentemente, para a dengue, chikungunya e outras doenças também transmitidas pelo Aedes. Tem-se delimitado políticas do Aedes que definem e legitimam as metodologias, tecnologias, intervenções e atores aptos a agir e a "resolver" o problema.

No entanto, a descoberta e confirmação científica de que há outras vias de transmissão do vírus que não somente pelo vetor, a doença causada pelo vírus Zika revelou outras dimensões. Até o momento, nove países relataram indícios de transmissão do vírus por via sexual. Outras vias de transmissão estão sendo estudadas, com várias possibilidades levantadas: por transmissão sexual (Foy et al., 2011; Musso et al., 2015b; Atkinson et al., 2016); por soro, saliva 
e urina (Gourinat, 2015; Musso et al., 2015a; Bonaldo et al., 2016); por leite materno (Dupont-Rouzeyrol et al., 2016); e por transfusão de sangue (Musso et al., 2014a). Importante, nesse contexto, é o fato de a Zika ter se tornado também uma "doença sexualmente transmissível", o que traz consigo todo um conjunto de conotações morais e abre as portas a práticas discriminatórias e estigmatizantes, como tem sido observado na mídia e em algumas campanhas de prevenção da doença no Brasil e no mundo.

Finalmente, a partir do debate sobre os determinantes e as condições sociais, econômicas e políticas que geram e perpetuam a propagação do vetor e do vírus, a Zika foi também enquadrada como "doença negligenciada" ou "da pobreza" - ainda que esse enquadramento tenha permanecido numa posição periférica em face da importância dada, por exemplo, às medidas de controle do vetor. As vozes que levantam o tema dos determinantes trazem ao debate questões relacionadas às falhas de financiamento e de pesquisa, que acabam por afetar desproporcionalmente populações vulneráveis em situações de risco (Pimenta, 2015). No Brasil, a crise atual de financiamento no setor público, especialmente no Sistema Único de Saúde (SUS), denota a relevância e urgência dessas questões.

Em suma, vários processos de significação têm competido e interagido na definição da epidemia de Zika como um problema de saúde. Não há um processo unívoco e nenhum desses significados captura a "verdade" sobre a epidemia - antes todas revelam dimensões do problema e aspectos relevantes na forma como este tem sido interpretado e enquadrado. Essas interpretações têm efeitos concretos, contribuindo para delimitar o âmbito de soluções possíveis e desejáveis, definindo as estratégias, as tecnologias e os atores que são capacitados e legitimados para intervir. 


\section{A reprodução de zonas negligenciadas}

Os processos de significação analisados são importantes não só pelo que determinam, mas também pelo que é silenciado, ignorado ou deixado à margem. Prosseguindo a análise crítica descrita anteriormente, debrucemo-nos sobre a forma como a busca de significado para essa epidemia tem contribuído para a reprodução de zonas negligenciadas. A definição de negligência adotada neste artigo é abrangente, incluindo não apenas as doenças ditas negligenciadas, mas também os determinantes sociais, os grupos ou populações. Refere-se ao processo pelo qual determinadas doenças recebem - por parte de políticos, mídia, pesquisadores, agências de fomento à pesquisa ou do público em geral - uma atenção menor do que seria de esperar dado o seu impacto econômico e social, e dado o sofrimento que causam aos indivíduos e famílias afetados. Determinantes são negligenciados quando o seu impacto na susceptibilidade à doença

32 não é estudado ou sequer reconhecido. Finalmente, uma população ou grupo negligenciado é aquele que é sistematicamente colocado numa posição de risco e vulnerabilidade em face de uma doença, ou que é excluído dos melhores cuidados de saúde existentes num dado contexto (Nunes, 2016).

A epidemia de Zika revela a presença de muitas questões negligenciadas. Este artigo irá se debruçar sobre quatro delas, que consideramos particularmente importantes - não só porque afetam a resposta a essa doença, mas também porque revelam dinâmicas mais profundas na saúde global, expondo dessa forma seus limites.

Em primeiro lugar, a atenção dada à Zika na agenda global e o enfoque na associação entre Zika e microcefalia têm sublinhado a suposta "novidade" da doença. A ideia da epidemia de Zika como emergência veio acentuar esse processo. No entanto, para milhões de brasileiros, a crise da Zika veio obscurecer um problema mais profundo - uma 
verdadeira emergência diária que afeta grandemente a vida dessas pessoas. Desde 1986, o Brasil sofre com epidemias de dengue de forma quase ininterrupta, e, atualmente, os quatro sorotipos do vírus circulam no país. Além disso, neste momento, o Brasil está atravessando uma tríplice epidemia, caracterizada pelo compartilhamento do mesmo inseto vetor por três vírus: dengue, chikungunya e Zika. Em 2015, mais de 1,5 milhão de casos de dengue foram notificados. Em 2016, foram registrados 802.429 casos prováveis de dengue entre janeiro e abril, com 140 óbitos confirmados. Em 2015, foram notificados 38.332 casos prováveis de febre de chikungunya, com 6 óbitos confirmados. Já em 2016, até o início de abril, foram notificados 39.017 casos prováveis de febre chikungunya no país, com 12 óbitos confirmados (SVS/MS, 2016a). Devido às dificuldades no diagnóstico diferencial e à sobrecarga dos sistemas e serviços de saúde, territórios com circulação de outras arboviroses enfrentam dificuldades acrescidas no controle do vírus Zika.

Esses dados mostram a gravidade de uma situação que tem, em grande medida, passado despercebida no contexto da saúde global - cuja agenda atual permanece quase exclusivamente focalizada na contenção do vírus Zika e na busca de soluções majoritariamente farmacológicas ou tecnológicas direcionadas a vacinas ou ao vetor. O Brasil, tal como muitos outros países do mundo, tem uma história de fracasso com relação ao controle e prevenção das arboviroses - que têm sido negligenciadas a ponto de se terem tornado, para muitos setores da população, fenômenos quase naturais e inevitáveis. No entanto, um árduo trabalho de três décadas tem resultado em importantes lições sobre as formas de enfrentamento dessas epidemias (Valle, Pimenta e Cunha, 2015). Antes da Zika, foi a experiência acumulada contra a dengue que permeou a preparação do serviço público brasileiro para a entrada no país da chikungunya. A expansão territorial da chikungunya desde 2004 suscitou 
o lançamento de um alerta da Organização Pan-Americana da Saúde, dirigido a todo o continente americano (Valle, Pimenta e Cunha, 2016). No entanto, a atual situação é o resultado de decisões (e omissões) políticas - nomeadamente graves falhas na prevenção, dependentes de muitos aspectos que extrapolam o setor da saúde. Em particular, merecem destaque aspectos macroestruturais, socioeconômicos e ambientais, historicamente ignorados em prol de intervenções meramente biomédicas ou tecnológicas. Existe o risco de que a atenção dada à Zika contribua para fazer esquecer uma vez mais a gravidade desse problema social, econômico e político, de médio e longo prazos, ao focar somente nos seus sintomas em detrimento de suas causas mais profundas.

Em segundo lugar, o controle da doença tem sido igualado ao controle do vetor, que, por sua vez, se baseia prioritariamente na sua redução, eliminação ou erradicação. Após mais 34 de um século da descoberta da transmissão vetorial do vírus da febre amarela e de outros agentes infecciosos, a base da tecnologia de controle dos transmissores (em especial, o Aedes) se mantém praticamente a mesma: destruição de focos que contêm ovos e larvas dos mosquitos e, a partir da década de 1940 (mais de setenta anos), a incorporação do uso de larvicidas e inseticidas (Santos et al., 2016). Essa estratégia funcionou até certo ponto no século passado com campanhas verticais contra a febre amarela lideradas por Oswaldo Cruz. No entanto, o controle do vetor teve vários fracassos ao longo da sua história (Esteves, 2016).

Observa-se hoje uma realidade totalmente diversa que conclama por novas estratégias de controle do vetor. Algumas já estão sendo implementadas, nomeadamente métodos tecnológicos de manipulação genética ou envolvendo bactérias. Porém, as ações de controle do vetor têm limites e não podem ser vistas como a única solução para o problema das arboviroses. Segundo Santos et al. (2016), não basta reduzir a 
infestação do Aedes aegypti, pois a força de transmissão dessas três arboviroses é muito elevada mesmo em situações de baixos níveis de infestação vetorial, por ser modulada pelo nível de imunidade de grupo existente em cada espaço. Infelizmente, as tecnologias disponíveis para combate vetorial, mesmo quando usadas integralmente (manejo integrado), como proposto pela OMS, não se têm mostrado muito efetivas.

Uma das consequências de se continuar a pensar nas arboviroses (e na Zika em particular) como um "problema de mosquito" é a perpetuação da negligência de determinantes políticos, econômicos e ambientais - ou seja, do contexto mais amplo onde a doença se instala e se reproduz. Enquanto o contexto político em que as respostas à Zika se inserem produz pressões sobre o governo, exigindo respostas com resultados imediatistas, a resolução do problema requer necessariamente mudanças profundas, estruturais e de longo prazo, que permitam enfrentar os fatores que estão impedindo o Brasil e o mundo de lidar adequadamente com as arboviroses. Torna-se urgente questionar e lidar com os problemas estruturais, universalizar o acesso à água tratada, coletar e dar destinação adequada ao lixo, expandir a oferta de saneamento, dentre outros. A doença tem revelado as contradições da sociedade brasileira e do mundo, bem como do atual modelo de desenvolvimento capitalista neoliberal, tais como: insuficiências do SUS e demais sistemas de saúde, problemas de saneamento, de abastecimento de água, necessidade de políticas de urbanização sustentável, entre outras questões de cunho social, econômico, político e cultural (Abrasco, 2016).

Em terceiro lugar, a epidemia de Zika revela a persistência de estruturas sociais, políticas e econômicas que reproduzem a desvantagem e vulnerabilidade de determinadas populações e grupos. Desde a década de 2000, doenças negligenciadas como a Zika têm sido reconhecidas como, simultaneamente, um resultado e um mecanismo perpetuador da 
pobreza (Hotez, 2013) - as denominadas, "doenças da pobreza" ou "doenças tropicais da pobreza". No contexto atual, alguns autores têm destacado que as arboviroses, e mais especificamente a Zika, atingem com particular intensidade as pessoas negligenciadas pelas políticas públicas - ou seja, as pessoas que não têm acesso a condições adequadas de habitação e saneamento, de infraestrutura sanitária e a melhor informação sobre prevenção de doenças(Aguiar e Araújo, 2016; Parsons, 2016; Kambale et al., 2016; LaBeaud, 2008).

No que diz respeito à microcefalia, a vulnerabilidade econômica assume um papel importante no sucesso das estratégias de planejamento familiar, com o acesso a contraceptivos e o direito ao aborto a serem condicionados pela situação econômica. O impacto das vulnerabilidades verifica-se ainda no nível da capacidade das redes de apoio (públicas, comunitárias e familiares) de amparar, por meio dos serviços, as crianças e famílias afetadas pela microcefa36 lia. No Brasil, a microcefalia resultante de Zika tem atingido com particular intensidade os estados do Nordeste, onde se verifica elevada incidência de pobreza. Dados de 30 de abril de 2016 mostram: Bahia (17,7\% da população vivendo em extrema pobreza; 232 casos confirmados de microcefalia), Pernambuco (16,1\% da população em extrema pobreza; 339 casos confirmados de microcefalia) e Paraíba (16,3\% da população em extrema pobreza; 115 casos confirmados de microcefalia). É importante ainda ressalvar que na Região Nordeste permanecem em investigação 2.544 casos de microcefalia (incluindo 645 na Bahia, 653 em Pernambuco e 379 em Paraíba) (SVS/MS, 2016b). Em outras palavras, é bastante provável que o problema aumente nos próximos meses, configurando uma crise de saúde pública em médio e longo prazos. Abordagens "neutras" e supostamente "apolíticas", centradas unicamente em instrumentos tecnológicos, farmacológicos e biomédicos, tendem a ignorar as desigualdades sistemáticas já existentes e - se forem 
desviadas as atenções da necessidade de transformações mais profundas - podem até contribuir para perpetuá-las.

A questão da pobreza e da vulnerabilidade é, portanto, fundamental para entender não só a incidência e distribuição de arboviroses (como a Zika), mas também a capacidade, ou incapacidade, de reagir perante as adversidades que delas podem advir (como a microcefalia). Outro aspecto fundamental nesse quadro é o gênero - que resulta do fato de a Zika ter sido enquadrada como um problema de mulheres (em idade fértil ou grávidas) e uma doença sexualmente transmissível. A epidemia de Zika suscita um conjunto de questões relacionadas aos desafios da sociedade patriarcal, nomeadamente no que diz respeito ao controle efetivo que muitas mulheres têm sobre a sua vida sexual, a liberdade de escolha na hora de gerenciar uma gravidez, o direito ao aborto e o direito à opinião e intervenção sobre as políticas que têm efeitos sobre o corpo feminino.

A epidemia de Zika e microcefalia afeta desproporcionalmente mulheres, particularmente aquelas de famílias vulneráveis. Os ministros da saúde de diferentes países da América Latina, incluindo o Brasil, fizeram recomendações públicas para mulheres e casais adiarem a gravidez. Essas recomendações parecem esquecer que $56 \%$ das gravidezes na região não são intencionais e que nem todas as mulheres têm acesso e controle sobre o uso de contraceptivos. Um quarto das mulheres na América Latina que desejavam evitar a gravidez não tiveram acesso a métodos contraceptivos confiáveis (Harris, Silverman e Marshall, 2016). A má qualidade da educação sexual, a falta de acesso à contracepção, a alta prevalência de estupro, bem como barreiras culturais e religiosas, que tornam difícil para as mulheres negociar o uso de contracepção com os seus parceiros, resultam em grandes grupos de mulheres que não têm controle sobre sua vida sexual e seus direitos reprodutivos. À luz disso, o surto revela as desigualdades sistêmicas de gênero em sociedades 
altamente patriarcais. Revela ainda o sexismo presente na sociedade brasileira, com o Ministro da Saúde Marcelo Castro a "torcer" para que mulheres fossem infectadas pela Zika antes do período fértil como forma de ganhar imunidade enquanto a vacina não está disponível. Em outra ocasião, o mesmo ministro observou ainda que as mulheres estão mais vulneráveis por ficarem de "perna de fora”, e prescreveu o uso de calças como medida preventiva (Martins, 2016).

Galli e Deslandes (2016) lembram que tal quadro conclama o debate público sobre o direito das mulheres de interromper a gravidez se assim o desejarem como uma questão de justiça social reprodutiva. Com relação ao aborto, o Brasil tem uma das legislações mais restritivas do mundo. Desde 1940, o aborto no Brasil é apenas permitido nos casos de risco de vida para a mulher quando há crime sexual e em caso de feto anencefálico. Os óbitos decorrentes de abortos clandestinos constituem uma das cinco principais 38 causas de morte materna evitável. Nesse contexto, várias organizações de direitos sexuais e reprodutivos apoiaram futura ação junto ao Supremo Tribunal Federal brasileiro solicitando autorização de interrupção da gravidez para mulheres infectadas com vírus Zika, com base nos riscos à sua saúde mental e nos riscos potenciais ao pleno desenvolvimento do feto. A argumentação central baseia-se na responsabilidade do Estado pelo não controle do vetor e na garantia do direito à dignidade e saúde das mulheres, considerando a situação de particular vulnerabilidade social e econômica que muitas atravessam.

Em síntese, o argumento demonstrou que a epidemia de Zika e sua associação com a microcefalia são muito mais do que um "problema de mosquitos" com somente intervenções tecnológicas ou farmacológicas. Abrangem, também, complexos problemas sociais e políticos. Relacionam-se ao fracasso sistemático do controle e prevenção às doenças negligenciadas no continente americano e no mundo. Tais 
problemas demonstram os limites de estratégias que negligenciam os determinantes políticos, econômicos, ambientais e infraestruturais. Revelam também as disparidades no acesso à informação e aos serviços e cuidados de saúde, demonstrando falhas importantes nas políticas de saúde reprodutiva no Brasil, ao mesmo tempo que ilustram uma vez mais a persistência de profundas desigualdades de gênero.

\section{$* * *$}

Este artigo explorou algumas problemáticas em âmbito político e social suscitadas pela epidemia de Zika no Brasil. Para além de revelar as tensões, contradições e desigualdades das políticas de saúde no país, a epidemia de Zika ilustra problemas mais abrangentes. As tensões políticas aqui identificadas - referentes ao controle das doenças negligenciadas, determinantes sociais e econômicos, classe e gênero - enquadram-se em dinâmicas que ultrapassam as fronteiras do país. Nesse sentido, o processo de significação e as respostas à epidemia de Zika e microcefalia são reveladoras dos atuais limites da saúde global.

Um dos limites que ficou evidente nesse contexto é o fato de a agenda da saúde global ser ainda predominantemente reativa: responde a crises e emergências em vez de contribuir de forma mais proativa para solucionar os problemas geradores das crises. Esse caráter reativo tem seu efeito sobre o caráter da atenção dada aos problemas. Em grande medida, os agentes da saúde global, ao centrarem os seus esforços na resposta à crise ou emergência mais importante "do momento", acabam por se pautar por uma atuação superficial e de curto prazo. O espetáculo midiático criado ao redor da epidemia de Zika - ao qual não são estranhas as imagens sensacionalistas de crianças com microcefalia e o fato de o Brasil ser o anfitrião dos Jogos Olímpicos este ano de 2016 - contribuiu para capturar durante algumas semanas 
a atenção da opinião pública mundial. Alvo de pressões políticas internas, o governo de Dilma Rousseff tentou mostrar uma face determinada e combativa, transformando a resposta numa verdadeira guerra nacional contra o mosquito. Entretanto, o problema das arboviroses afeta o Brasil e o mundo há décadas, e uma resolução dos problemas sociais, econômicos e culturais que estão na sua origem não se compadece com ciclos midiáticos e eleitorais de curto prazo.

A saúde global continua a negligenciar questões macroestruturais dos processos de saúde-doença e o problema da determinação social das doenças, privilegiando fortemente uma perspectiva puramente tecnológica e biomédica. A recente tendência para a securitização de doenças tem sido em grande parte uma oportunidade perdida, uma vez que contribui para reproduzir uma lógica de medidas excepcionais e de curto prazo, que não se traduzem necessariamente em melhoria da qualidade da atenção. Quando interpretadas 40 como problemas de segurança, as doenças acabam por se ver enredadas numa lógica imediatista de contenção e gestão de crises, ao mesmo tempo que é dificultada a possibilidade de uma participação democrática e que inclua os pontos de vista dos grupos e comunidades mais afetados e vulneráveis.

O predomínio de uma lógica de contenção de crises significa também que a saúde global continua privilegiando os interesses das nações desenvolvidas. Na maioria das vezes, continuam sendo privilegiadas as doenças infecciosas que têm o potencial de atingir os países do hemisfério Norte, não se implementando medidas e políticas mais igualitárias que permitam reduzir as grandes desigualdades que ainda persistem na saúde global. Nesse contexto, a saúde global continua a sistematicamente refletir e reproduzir a dinâmica centro-periferia que está na sua gênese. Dinâmicas coloniais continuam a fazer-se sentir, visíveis, por exemplo, na forma paternalista como o saber científico e as capacidades dos profissionais e comunidades dos países do Sul são vistos 
por muitos responsáveis e cientistas do Norte. Esse paternalismo está também presente na forma como o Brasil é visto, como essencialmente incapaz de solucionar o problema, necessitando de ser "salvo" por países mais desenvolvidos, como tem sido amplamente discutido nos meios midiáticos internacionais.

Finalmente, a epidemia de Zika mostra uma vez mais como a agenda da saúde global negligencia a diversidade de experiências e as múltiplas reproduções de desigualdades, contribuindo para perpetuar, há décadas, iniquidades relacionadas a gênero, raça e classe social - entre outras categorias fundamentais para uma compreensão plena da saúde e da doença.

Este artigo sugeriu uma abordagem crítica à epidemia de Zika e à saúde global, assente em quatro eixos fundamentais. Falta apontar um aspecto importante dessa abordagem: o fato de os seus propósitos não terem unicamente o intuito de identificar problemas, mas também o de identificar, explicitamente, alternativas, intervenções e soluções. Dito de outro modo, a crítica da saúde parte da análise de situações concretas para identificar o potencial emancipatório. Assim, por um lado, a ideia não é meramente descrever dinâmicas ou experiências, mas entendê-las no contexto de reprodução de vulnerabilidades e de formas de violência estrutural, que devem ser questionadas e mudadas (Anderson, 2015). Esse "passo seguinte" da análise crítica contempla ainda a identificação de possibilidades de transformação, sob a forma de ideias alternativas ou atores engajados na transformação política. Este artigo identificou alguns desses recursos transformadores, nomeadamente a ideia da sustentabilidade urbana, a importância dada aos determinantes da saúde e a ênfase nas vulnerabilidades específicas de certas populações e grupos.

Essa transformação pretende-se emancipatória na medida em que visa contribuir para alargar o espaço de 
reflexão e ação, permitindo aos indivíduos e grupos maior autonomia para tomarem decisões e agirem nas questões que determinam sua própria vida. A saúde é aqui vista como uma esfera da vida na qual é possível identificar constrangimentos ou obstáculos à livre determinação de cursos de vida. A doença é um desses obstáculos, tal como as barreiras no acesso aos cuidados de saúde ou a melhor informação sobre prevenção de doenças. O trabalho emancipatório de uma abordagem crítica implica identificar esses obstáculos e trabalhar para a sua superação ou diminuição.

\section{João Nunes}

é professor de Relações Internacionais na Universidade de York, Reino Unido.

\section{Denise Nacif Pimenta}

é pesquisadora do Centro de Pesquisas René Rachou, da 42 Fundação Oswaldo Cruz (Fiocruz), em Minas Gerais.

\section{Bibliografia}

ABRASCO - Associação Brasileira de Saúde Coletiva. 2016. Cidades sustentáveis e saudáveis: microcefalia, perigos do controle químico e o desafio do saneamento universal. Disponível em: <https://www.abrasco. org.br/site/2016/02/carta-de-alerta-da-abrasco-cidades-saudaveis-esustentaveis-este-e-o-desafio-urgente/>. Acesso em: fev. 2016.

AGUIAR, R.; ARAUJO, I. S. 2016. A mídia em meio às "emergências" do vírus Zika: questões para o campo da comunicação e saúde. RECIIS - Revista eletrônica de comunicação, informação \& inovação em Saúde, v. 10, n. 1.

ANDERSON, E.-L. 2015. Gender, HIV and risk: navigating structural violence. Houndmills: Palgrave Macmillan.

ANDERSON, W. 2006. Colonial pathologies: American tropical medicine, race, and hygiene in the Philippines. Durham/London: Duke University Press. ATKINSON, B. et al. 2016. Detection of Zika virus in semen [letter]. Emerging Infectious Diseases, v. 22, n. 5. Disponível em: <http://wwwnc. cdc.gov/eid/article/22/5/16-0107_article>. Acesso em: 29 jun. 2016. AYRES, C. F. J. 2016. Identification of Zika virus vectors and implications for control. The Lancet-Infections Diseases, v. 16, n. 3, pp. 278-79. 
BIRN, A-E. 2009. The stages of international (global) health: histories of success or successes of history?". Global Public Health, n. 4, pp. 50-68.

BONALDO, M. C. et al. 2016. Isolation of infective Zika virus from urine and saliva of patients in Brazil. PLOS Neglected Tropical Diseases. Disponível em: <http://journals.plos.org/plosntds/article?id=10.1371/ journal.pntd.0004816>. Acesso em: 29 jun. 2016.

BOORMAN, J. P.; PORTERFIELD, J. S. 1956. A simple technique for infection of mosquitoes with viruses; transmission of Zika virus.

Transactions of the Royal Society of Tropical Medicine and Hygiene, n. 50, pp. 238-42.

BRASIL. Presidência da República. Casa Civil. Subchefia para Assuntos Jurídicos. 2011. Decreto n ${ }^{\circ}$ 7.616, de 17 de novembro de 2011. Dispõe sobre a declaração de Emergência em Saúde Pública de Importância Nacional - ESPIN e institui a Força Nacional do Sistema Único de Saúde - FN-SUS. Disponível em: <http://www.planalto.gov.br/ccivil_03/_ Ato2011-2014/2011/Decreto/D7616.htm>. Acesso em: 29 jun. 2016.

BROWN, T. M.; CUETO, M.; FEE, E. 2006. The World Health Organization and the transition from "international" to "global" public health. American Journal of Public Health, n. 96, pp. 62-72.

COOPER, A. F.; KIRTON, J. J.; STEVENSON, M. A. 2009. Critical cases in global health innovation. In: COOPER, A. F.; KIRTON, J. J. (eds.). Innovation in global health governance: critical cases. Farnham: Ashgate. CUETO, M. 2015. Saúde global: uma breve história. Rio de Janeiro: Fiocruz. DICK, G. W.; KITCHEN, S. F.; HADDOW, A. J. 1952. Zika virus. I. Isolations and serological specificity. Transactions of the Royal Society of Tropical Medicine and Hygiene, n. 46, pp. 509-20.

DUPONT-ROUZEYROL, M. et al. 2016. Infectious Zika viral particles in breastmilk. The Lancet, v. 387, n. 10023, pp. 1051.

EDMOND, R. 2006. Leprosy and empire: a medical and cultural history. Cambridge: Cambridge University Press.

ESTEVES, B. 2016. A guerra dos cem anos: por que o Brasil não consegue vencer o Aedes aegypti. Piaui, n. 115, pp. 20-29.

FASSIN, D. 2012. That obscure object of global health. In: INHORN, M. C.; WENTZELL, E. A. (eds.). Medical anthropology at the intersections: histories, activisms, and futures. Durham/London: Duke University Press. FIDLER, D. P. 2005. From international sanitary conventions to global health security: the new international health regulations. Chinese Journal of International Law, n. 4, pp. 325-92.

FOUCAULT, M. 1977. Discipline and punish: the birth of the prison. London: Allen Lane. 
FOY, B. D. et al. 2011. Probable non-vector-borne transmission of Zika virus, Colorado, USA. Emerging Infectious Diseases, n. 17, pp. 880-82.

GALLI, B.; DESLANDES, S. 2016. Ameaças de retrocesso nas políticas de saúde sexual e reprodutiva no Brasil em tempos de epidemia de Zika. Cadernos de Saúde Pública, v. 32, n. 4. Disponível em: <http://www.scielo. br/scielo.php?script=sci_arttext\&pid=S0102-311X2016000400301>. Acesso em: 12 jul. 2016.

GONZÁLEZ, S. 2016. Zika y Zikafobia: una página en construcción. Archivos de Pediatría del Uruguay, v. 87, n. 1, pp. 53-61.

GOURINAT, A. C. 2015. Detection of Zika virus in urine. Emerging Infectious Diseases, v. 21, n. 1, pp. 84-86.

HARRIS, L. H.; SILVERMAN, N. S.; MARSHALL, M. F. 2016. The paradigm of the paradox: women, pregnant women, and the unequal burdens of the Zika virus pandemic. The American Journal of Bioethics, v. 16, n. 5, pp. 1-4.

HEYMANN, D. L. 2016. Zika virus and microcephaly: why is this situation a PHEIC? The Lancet, v. 387, n. 10020, pp. 719-21.

HOTEZ, P. J. 2013. Forgotten people, forgotten diseases: the neglected tropical diseases and their impact on global health and development. Washington, DC: ASM Press.

KAMBALE, T. et al. 2016. Zika virus infection: the resurgence of a neglected disease. Medical Journal of Dr. DY Patil University, v. 9, n. 2, pp. 283-87.

KING, N. B. 2002. Security, disease, commerce: ideologies of postcolonial global health. Social Studies of Science, n. 32, pp. 763-89.

KRAUT, A. M. 1994. Silent travelers: germs, genes and the "immigrant menace". Baltimore/London: The Johns Hopkins University Press.

LABEAUD, A. D. 2008. Why arboviruses can be neglected tropical diseases? PLOS Neglected Tropical Diseases, v. 2, n. 6. Disponível em: http:/ /journals.plos.org/plosntds/article?id=10.1371/journal. pntd.0000247>. Acesso em: 12 jul. 2016.

MACNAMARA, F. N. 1954. Zika virus: a report on three cases of human infection during an epidemic of jaundice in Nigeria. Transactions of the Royal Society of Tropical Medicine and Hygiene, n. 48, pp. 139-45.

MARKEL, H. 1997. Quarantine!: East European Jewish immigrants and the New York City epidemics of 1892. Baltimore/London: The Johns Hopkins University Press.

MARTIN, E. 1994. Flexible bodies: the role of immunity in American Culture from the days of polio to the Age of AIDS. Boston: Beacon Press.

MARTINS, R. 2016. O Zika e o descaso na saúde pública. Carta Capital. Disponível em: <http://www.cartacapital.com.br/revista/886/e-hajamosquitos $>$. Acesso em: 30 jun. 2016. 
MUSSO, D. et al. 2014a. Potential for Zika virus transmission through blood transfusion demonstrated during an outbreak in French Polynesia November 2013 to February 2014. Euro Surveillance, v. 19, n. 14, pp. 1-3. . 2014b. Rapid spread of emerging Zika virus in the Pacific area. Clinical Microbiology Infections, n. 20, pp. 595-96. 2015a. Detection of Zika virus in saliva. Journal of Clinical Virology, n. 68 , pp. 53-55. 2015b. Potential sexual transmission of Zika virus. Emerging Infectious Diseases, n. 21, pp. 359-61.

NUNES, J. 2016. Ebola and the production of neglect in global health. Third World Quarterly, v. 37, pp. 542-56.

PAHO/WHO - Pan American Health Organization/World Health Organization [OPAS - Organização Pan-Americana de Saúde/OMS Organização Mundial de Saúde]. 2016. Zika Epidemiological Update, 21 Apr., Washington, D.C., PAHO/WHO.

PARSONS, M. 2016. We've neglected diseases like the Zika virus for too long. Time Magazine, jan. Disponível em: <http://time.com/4193072/ zika-virus-neglected-disease/>. Acesso em: jan. 2016.

PIMENTA, D. N. 2015. A (des)construção da dengue: de tropical a negligenciada. In: VALLE, D.; PIMENTA, D. N.; CUNHA, R. V. (orgs.). Dengue: teorias e práticas. Rio de Janeiro: Fiocruz.

2016. Zika, dengue, chikungunya: mosquito bom é mosquito morto?. Revista Ciência Hoje, n. 336. Disponível em: <http://www. cienciahoje.org.br/revista/materia/id/1022/n/mosquito_bom_e_ mosquito_morto $>$. Acesso em: 29 jun. 2016.

SANTOS, D. N. et al. 2016. Documento de posição sobre a tríplice epidemia de Zika-dengue-chikungunya. Observatório de Análise Política em Saúde. Disponível em: <https:/ /www.abrasco.org.br/site/wp-content/uploads/2016/03/ Documento-posi\%C3\%A7\%C3\%A3o-sobre-a-epidemia-de-zika.pdf>.

SHAH, N. 2001. Contagious divides: epidemics and race in San Francisco's Chinatown. Berkeley: University of California Press.

SHUM, T. T. 2016. Discussion: Zika - an epidemic of signification? Disponível em: <http://somatosphere.net/forumpost/discussion-zikaan-epidemic-of-signification>. Acesso em: fev. 2016.

SVS/MS - Secretaria de Vigilância em Saúde/Ministério da Saúde. 2016a. Monitoramento dos casos de dengue, febre de chikungunya e febre pelo vírus Zika até a Semana Epidemiológica 13, 2016. Boletim Epidemiológico, v. 47, n. 18. Disponível em: <http://portalsaude.saude. gov.br/images/pdf/2016/abril/27/2016-014-Dengue-SE13-substitui-o.pdf>. Acesso em: 30 jun. 2016. 
2016b. Monitoramento dos casos de microcefalia no Brasil.

Informe Epidemiológico, n. 24. [Semana 24 a 30 abr. 2016]. Disponível em: <http://portalsaude.saude.gov.br/images/pdf/2016/maio/04/coesmicrocefalia-informe-epi-24-se17-2016.pdf>. Acesso em: 30 jun. 2016.

TREICHLER, P. A. 1987. Aids, homophobia and biomedical discourse: an epidemic of signification. Aids: Cultural Analysis/Cultural Activism, n. 43, pp. 31-70.

VALLE, D.; PIMENTA, D. N.; AGUIAR, R. 2016. Zika, dengue e chikungunya: desafios e questões. Epidemiologia e Serviços de Saúde, v. 25, n. 2. Disponível em: <http://scielo.iec.pa.gov.br/scielo.php?pid=S1679$49742016000200419 \&$ script=sci_arttext $>$. Acesso em: 29 jun. 2016.

VALLE, D.; PIMENTA, D. N.; CUNHA, R. V. (orgs.) 2015. Dengue: teorias e práticas. Rio de Janeiro: Fiocruz.

VENTURA, D. 2016. From Ebola to Zika: international emergencies and the securitization of global health. Cadernos de Saúde Pública [on-line], v. 32, n. 4.

WEIR, L.; MYKHALOVSKIY, E. 2010. Global public health vigilance: creating a world on alert. Abingdon: Routledge.

WHO - World Health Organization [OMS - Organização Mundial de Saúde]. 2016. Situation report. May. Disponível em: <http://www.who. int/emergencies/zika-virus/situation-report/5-may-2016/en/>. Acesso em: 27 jun. 2016.

ZACHER, M. W.; KEEFE, T. J. 2008. The politics of global health governance: united by contagion. Houndmills: Palgrave Macmillan.

ZANLUCA, C. et al. 2015. First report of autochthonous transmission of Zika virus in Brazil. Memórias do Instituto Oswaldo Cruz, n. 110, pp. 569-72. 


\section{A EPIDEMIA DE ZIKA E OS LIMITES DA SAÚDE GLOBAL}

JOÃO NUNES

\section{DENISE NACIF PIMENTA}

Resumo: O vírus Zika foi isolado pela primeira vez em 1947 em Uganda. Se a doença existe desde então, por que somente agora há atenção da mídia, da ciência, das agências financiadoras e dos órgãos nacionais e internacionais? A partir de uma visão crítica da saúde global, que considera os contextos sociais, políticos e ideológicos, nos quais a Zika é enquadrada, almeja-se analisar a atual epidemia de Zika em quatro eixos: (1) investigação dos processos sociais, culturais e políticos; (2) análise das práticas de significação; (3) estudo das zonas negligenciadas/silenciadas; e (4) atenção à diversidade de experiências individuais de saúde e de doença. As tensões políticas aqui identificadas e discutidas - referentes ao controle das doenças negligenciadas, determinantes sociais, de classe e de gênero - enquadram-se em dinâmicas que ultrapassam as fronteiras nacionais. Nesse sentido, os processos de significação e as respostas dadas à epidemia mostram os atuais limites da saúde global.

Palavras-chave: Zika; Saúde Global; Doenças Negligenciadas; Políticas de Saúde.

\section{THE ZIKA EPIDEMIC AND THE LIMITS OF GLOBAL HEALTH}

Abstract: Zika virus was first isolated in 1947 in Uganda. If the disease has existed since then, why is it only now that there is attention from the media, science, funding agencies and national and international bodies? From the standpoint of critical global health that considers the social, political and ideological contexts which Zika is framed, we aim to analyse the Zika epidemic in four aspects: (1) investigation of the social, cultural and political processes; (2) analysis of signification practices; (3) study of 
neglected/silenced zones; and (4) attention to the diversity of individual experiences related to health and disease. The political tensions here identified and discussed - related to the control of neglected diseases, social, class and gender determinants - fall into dynamics, which go beyond national borders. In this sense, processes of signification and responses to the epidemic show the current limits of global health.

Keywords: Zika; Global Health; Neglected Diseases; Health Policies.

Recebido em: 9/5/2016 Aprovado em: 17/6/2016 